\title{
DESCOBRIR E REDESCOBRIR 0 GRANDE RIO DAS AMAZONAS. AS RELACIONES DE CARVAJAL (1542), ALONSO DE ROJAS SJ (1639) E CHRISTÓBAL DE ACUÑA SJ (1641)"
}

\author{
Maria Cristina Bohn Martins \\ Prof ${ }^{a}$ Titular dos Cursos de Graduação e Pós-Graduação em História da Universidade \\ do Vale do Rio dos Sinos - UNISINOS
}

\section{Resumo}

$\mathrm{O}$ artigo analisa três narrativas acerca da conquista européia da América. Tratam-se das "relaciones" de Carvajal, Rojas e Acuña, as quais, escritas entre 1542-1641, contribuem para repertoriar o espaço amazônico, assim como para construí-lo simbolicamente.

\section{Pallavras-Chave}

Amazônia • Textos Coloniais • Discursos Narrativos

\section{Abstract}

The present article analyzes the work called "relaciones", which was written between 1542 and 1641 respectively by the Dominican friar G. de Carvajal and the Jesuits A. Rojas and C. Acuña. The objective is to understand the way they have contributed to simbolically build the Amazon space while describing it.

\section{Keywords}

The Amazon • Colonial Texts • Narrative Discourses

\footnotetext{
"A pesquisa para a elaboração deste trabalho contou com o auxílio dos alunos bolsistas de Iniciação Científica Davi Jardim (FAPERGS), Deise C. Schell (PIBIC) e Maiquel P. Rasquin (UNIBIC).
} 
Desde seus momentos iniciais, o processo de descobrimento, conquista e colonização espanhola da América fez-se acompanhar de uma intensa e extensa elaboração discursiva. Diários, cartas e informes inicialmente e, depois, leis, crônicas e histórias, entre outros, formam um corpus textual que pode ser organizado em vários tipos discursivos ${ }^{1}$. Entre eles encontram-se as "relações do descobrimento e da conquista" como as que, referentes à Amazônia dos séculos XVI e XVII, estudamos neste artigo. O que propomos para tanto é analisar como os imperativos de escolha de um dado tipo discursivo, as suas qualidades formais, bem como as condições políticas em que ele foi produzido, incidem sobre o que veio a ser narrado.

\section{Os "Marañones" e o Grande Rio}

Em meados de setembro de 1542, um grupo de homens a pé, seminus, doentes e famintos, chegou a Quito em meio à surpresa dos que os observavam. Eles eram capitaneados por Gonzalo Pizarro, irmão do poderoso conquistador do Peru, e haviam participado com ele da primeira grande expedição européia a explorar a Amazônia. Segundo o Padre João Daniel, missionário jesuíta do século XVIII ${ }^{2}$, resultou daí um dos nomes pelo qual o rio seria então conhecido entre os espanhóis: o Marañon.

Desta mesma tropa de Pizarro lhe vem o terceiro nome (...) porque (...) recebidos como homens ressuscitados (...) e perguntados pelo que tinham visto e observado, e que notícias traziam do lago Dourado e da rica cidade de Manoa (...) respondiam que tudo eram maranhas e mais

\footnotetext{
${ }^{1}$ Sobre os tipos discursivos pelos quais se organiza a prosa narrativa do período colonial hispano-americano, ver: MIGÑOLO, Walter D. Cartas, crónicas y relaciones del descubrimiento y de la conquista. In : MADRIGAL, Iñigo (ed). Historia de la literatura hispanoamericana (Época colonial). Madrid: Cátedra, 1982, p. 57-116.

${ }^{2}$ O jesuíta João Daniel (1722-1776), autor do Tesouro descoberto no máximo rio das Amazonas, viveu na Amazônia entre 1741-1757 de onde foi expulso para viver os seguintes 18 anos nos cárceres de Lisboa (1757 - 1776), onde veio a falecer. Durante este período, escreveu um notável painel sobre a região, dividido em três partes: a Terra, o Homem e a Cultura, em que informa minuciosamente sobre suas populações e costumes, flora, flauna e geografia. Supõe-se que a obra foi redigida, parte no forte de Almeida, onde esteve entre 1758 - 1762, e parte na torre de São Julião, onde viveu seus últimos quatorze anos de reclusão (DANIEL, João. Tesouro Descoberto no Máximo Rio das Amazonas. Rio de Janeiro: Contraponto, 2004).
} 
maranhas, queriam dizer que tudo eram matos, lagoas, pântanos, voltas, rodeios e labirintos, por onde tinham andado embaralhados. Foi-se divulgando pouco a pouco o nome maranhas, até que ficou com alguma mudança perpetuado no rio o nome Maranhão; e assim o chamam os castelhanos propriamente desde o rio Pongo até as suas cabeceiras... ${ }^{3}$

A partir desta viagem inaugural, entre os séculos XVI e XVIII, um importante conjunto de relatos sobre a Amazônia foi produzido por diversos sujeitos, fossem eles aventureiros, funcionários das Coroas ibéricas ou missionários. Neles podemos encontrar dados que destoam da noção, por muito tempo corrente, de que a floresta tropical fosse pouco adequada para a sobrevivência humana e carente de recursos que viabilizassem a concentração e o desenvolvimento populacional. À medida em que estudos arqueológicos atuais fazem avançar uma nova compreensão sobre o passado da região, parece ser possível referendarem-se informações provenientes destes textos, especialmente quanto ao tamanho e complexidade das aldeias que se espalhavam pela várzea do Rio Amazonas. A imagem que assoma da sua calha a partir daí é a de "grandes populações reunidas em povoados de dimensões consideráveis, estruturas públicas com função político-cerimonial, capacidade de mobilização de numerosos guerreiros e existência de articulação social entre diferentes povoados" ". Esta é uma primeira acepção para o que chamamos "descobrir e redescobrir o Rio das Amazonas".

Tendo sido outrora em boa parte desconsideradas por conta de abrigar informações claramente fantasiosas - das quais aquelas relativas às lendárias amazonas é a mais conhecida -, as Relaciones vêm sendo recuperadas contemporaneamente como importante fonte de estudos. Efetivamente, à medida em que a historiografia das últimas duas décadas do século XX não apenas introduziu novos objetos ao seu questionário, como também novos princípios de inteligibilidade, novos modelos de compreensão, inclusive com alguns movimentos fundamentais no campo de observação, temas ligados ao rol do imaginário ou das representações passaram a freqüentar a agenda dos pesquisadores. E para estes, sem dúvida, assim como para aqueles que dizem respeito às sociedades indígenas pré-coloniais, as "Relações da Conquista e do Descobrimento" têm muito que acrescentar.

\footnotetext{
${ }^{3}$ DANIEL, João. Tesouro Descoberto no Máximo Rio das Amazonas, op. cit., p. 50.

${ }^{4}$ FAUSTO, Carlos. Os índios antes do Brasil. Rio de Janeiro: Jorge Zahar Ed., 2000, p. 45.
} 
Segundo Juliana Pedro, por exemplo, entre os múltiplos sentidos que se poderia atribuir à expressão "descobrimento" nos escritos coloniais, é possível encontrarmos, tanto os termos da construção de uma autoridade legal sobre a região, aspecto que é o que nos interessa neste artigo, como outros, que são os que elaboram uma memória a seu respeito ${ }^{5}$. Realmente, alguns destes documentos acabaram constituindo-se, muitas vezes, em material quase único para o conhecimento das sociedades indígenas que ocupavam as margens do rio, uma vez que a maior parte delas veio a desaparecer em conseqüência do domínio colonial europeu sobre o território. Sabemos, efetivamente, que as populações ribeirinhas foram sendo dizimadas e substituídas por contingentes de índios de terra firme, de variadas línguas e culturas, trazidos à força pelas tropas de resgate ${ }^{6}$. De acordo com Porro, estes, que viriam a ser os caboclos amazônicos, "assimilaram uma série de técnicas essenciais à sobrevivência na área, mas as antigas sociedades ribeirinhas, altamente integradas e adaptadas àquele ecossistema específico, haviam desaparecido para sempre"7.

A escassa informação histórica que dispomos sobre elas, portanto, é a que provêm destes primeiros registros, inaugurados pela crônica do dominicano Gaspar de Carvajal, que acompanhou a expedição de Francisco de Orellana de 1541-1542, a primeira a percorrer o rio desde suas nascentes até o Oceano Atlântico. A expedição em busca do País da Canela, principiada em Quito, em fevereiro de 1541, sob a chefia de Gonzalo Pizarro, compunha-se, inicialmente, de mais de duzentos espanhóis a cavalo, cerca de quatro mil índios para transporte e deslocou-se acompanhada de um incrível número de lhamas, porcos e cães. Depois de atravessar as terras geladas da Cordilheira em meio a imensas dificuldades, a região da canela revelou-se um desalento: além de a espécie americana ser de qualidade inferior àquela obtida no Oriente, sua presença descon-

\footnotetext{
${ }^{5}$ PEDRO, Juliana de Castro. Embates pela memória: narrativas de descoberta nos escritos coloniais da Amazônia Ibérica. Dissertação (Mestrado em História) - Pontifícia Universidade Católica de São Paulo, 2006. Disponível em: <http://www.dominiopublico.gov.br/ download/texto/cp008079.pdf>. Acessado em 05 de dezembro de 2006.

${ }^{6} \mathrm{O}$ nome aludia ao fato de que a intervenção européia "resgataria" os índios da vida pagã e do cativeiro decorrente das guerras intertribais.

${ }^{7}$ PORRO, Antonio. As Crônicas do rio Amazonas: Notas Etno-Históricas sobre as antigas populações indígenas da Amazônia. Petrópolis: Vozes, 1993, p. 08.
} 
tínua na floresta inviabilizava a exploração. A frustração não impediu que os homens seguissem viagem animados por outro mito, o do El Dorado, que acreditavam localizar-se em algum ponto da selva sul-americana.

Reduzido e acossado pela fome e por índios hostis, o grupo separou-se em fins de 1541 em um ponto indeterminado do rio Coca. Ficando Pizarro com a maioria dos homens, Orellana foi encarregado de, com um pequeno contingente, seguir pelo rio, em um bergantin que haviam construído, a fim de buscar alimentos. É justamente à viagem seguindo o curso do Amazonas que se refere o texto escrito pelo frei Gaspar de $\mathrm{Carvajal}^{8}$, que constrói-se, de fato, como uma tentativa de justificação para o descumprimento do acordo feito de regressarem, ele e seus companheiros, em auxílio dos demais, após a obtenção de víveres. Nesta mesma medida, trata-se, também, da narrativa dos percalços vividos pelo grupo que, depois de nove meses de dificuldades, em agosto de 1542, alcançou a foz do Marañon - que recebeu, daí, o nome de Rio de Orellana -, dirigindo-se, então, para a ilha de Cubágua, ao norte da Venezuela.

Ainda que a viagem não tenha alcançado seus objetivos, as notícias dela procedentes realimentaram a crença na existência de reinos fabulosos, de riquezas incontáveis, perdidos no coração da floresta: El Dorado, o País das Esmeraldas, a Terra da Canela, a cidade de Manoa, o Paititi ou outros. Em busca deles, ulteriores aventureiros percorreram o Grande Rio nos anos seguintes e produziram, desta forma, seus próprios registros. Retomados contemporaneamente e submetidos aos necessários procedimentos de crítica, estes documentos são, como já afirmamos, um excelente viés para estudar-se o passado da região, inclusive revisando algumas interpretações firmadas sobre ele.

Assim, em 1559 uma nova expedição, agora proveniente do Peru9 e animada pelos relatos dos sobreviventes do grupo de Orellana, foi organizada por Pedro de Ursúa. O assassinato do comandante e a rebelião de Lope de Aguirre, que se

\footnotetext{
${ }^{8} \mathrm{O}$ texto desta primeira viagem de navegação pelo Amazonas foi preservado através de duas cópias: uma conservada na Biblioteca da Real Academia de História e outra que, tendo sido doada à Bilbioteca Nacional de Madrid, pertenceu ao Duque de T'Serclaes de Tilly. A Relación foi conhecida por Gonzalo Fernández de Oviedo que a incluiu em sua Historia General de las Índias, assim como Pedro Cieza de León o fez em sua Crónica del Peru.

${ }^{9}$ A viagem de Orellana e Gonzalo Pizarro pelo Amazonas havia sido planejada e executada desde o chamado núcleo quitenho, região que se encontrava sob o governo de Gonzalo Pizarro, irmão do "conquistador do Peru".
} 
fez nomear Rei pelos expedicionários, talvez expliquem a existência de várias Relações e documentos relativos a esta célebre campanha. Os envolvidos nesta "Jornada para Omágua y Dorado" compunham um grupo numeroso e em boa parte formado pelos "deserdados da Conquista", homens que não haviam obtido o quinhão desejado no Peru e se apresentavam "ávidos de riquezas fáceis ou ressentidos com a falta de recompensa pelo que faziam nas Índias"10. A viagem foi marcada pela traição e violência e concluiu-se em julho de 1561 .

Os insucessos recorrentes, bem como o atrativo representado pela descoberta do Cerro Rico de Potosi ${ }^{11}$, acabaram por redirecionar o interesse dos espanhóis e, durante as décadas seguintes, não foram organizadas novas expedições na região. Sua presença na área permaneceu pouco significativa no século XVI, para tomar corpo na centúria seguinte como resultado de um movimento que, a partir dos Andes, avançava em direção ao leste ${ }^{12}$. Por outro lado, os portugueses, desde os inícios do XVII, haviam começado a se estabelecer na foz do rio ${ }^{13}$, tendo a fusão das coroas de Portugal e Espanha (1580 - 1640) contribuído para esmaecer limites e facilitar o trânsito dos luso-brasileiros em território espanhol e vice-versa. De outra parte, a União Ibérica significou a transferência, aos portugueses, de inimizades tradicionais da Coroa Espanhola, especialmente com a Inglaterra, França e Holanda. Encontramos, assim, os súditos, destes últimos, erigindo feitorias e sendo combatidos em vários pontos do Baixo Amazonas.

É neste contexto que os portugueses, estabelecidos na Vila de Nossa Senhora de Belém, foram surpreendidos pela chegada, em 1637, de uma canoa em que, acompanhados de seis soldados, dois leigos franciscanos haviam empreendido uma longa e quase inacreditável navegação pelo rio. Andrés de Toledo e

\footnotetext{
${ }^{10}$ UGARTE, Auxiliomar Silva. Margens Míticas: a Amazônia no imaginário europeu do século XVI. In: DEL PRIORE, Mary e GOMES, Flávio (org.). Os Senhores dos Rios. Amazônia, Margens e Histórias. Rio de Janeiro: Elsevier, 2003, p. 22.

${ }^{11}$ Os veios de prata de Potosí tornaram-se conhecidos dos europeus desde 1545.

${ }^{12}$ A criação das primeiras cidades na Amazônia peruana (Valladolid, Loyola, Santiago de la Montaña, Santa Maria de la Nieva e Logroño de los Caballeros), ainda no XVI, não deve conduzir a uma falsa idéia sobre a efetividade dos assentamentos hispânicos, muito instáveis ainda em inícios do XVII. Contudo, mesmo escassa, a presença espanhola e o regime de encomiendas havia contribuído para criar um forte clima de hostilidade com os indígenas. Precisamente por isto, a presença de missões religiosas na área pretendia responder às necessidades de segurança destas povoações (DOWNES, 2005, p. 152)

${ }^{13}$ Tendo fundando aí o forte do Presépio, depois Vila de Belém do Pará, em 1616.
} 
Domingos de Brieva eram sobreviventes de uma missão dirigida pelo Frei Laureano de la $\mathrm{Cruz}^{14}$, entre índios encabelados da região do rio Napo.

Não existem notícias de que a viagem tenha sido documentada e as informações sobre ela procedem de uma crônica anônima, cuja autoria foi atribuída, pelo erudito espanhol Marcos Jiménez de la Espada ${ }^{15}$, ao jesuíta Alonso de Rojas ${ }^{16}$. Supõe-se que, em Quito, tendo tido acesso a informações sobre ela, o jesuíta tenha escrito, em 1639, o "Descubrimiento del Rio de las Amazonas y sus dilatadas provincias...", principal fonte documental da viagem do grupo. A obra parece ter tido pouca divulgação e foi editada tão somente entre 1880 e $1889^{17}$.

Em que pese o fato de a Península Ibérica encontrar-se sob a mesma Monarquia, as autoridades locais sobressaltaram-se com a possibilidade de que o conhecimento da rota encorajasse outros empreendimentos espanhóis. Por isto, organizaram uma frota que deveria subir o Amazonas e o Napo até Quito para,

\footnotetext{
${ }^{14}$ Os encabelados, que parecem ter recebido este nome em virtude do cuidado com que trançavam e expunham suas longas cabeleiras, ocupavam a região do rio Napo. A missão dos franciscanos aí localizada teve que ser abandonada apressadamente diante de uma rebelião destes índios. O superior Laureano de la Cruz seguiu para Quito enquanto os freis Andrés de Toledo e Domingos de Brieva preferiram aventurar-se acompanhados por seis soldados que se propuseram seguir pelo rio até Belém. Um deles era o português Francisco Fernandes que já havia vivido no Pará e tinha relativo conhecimento da área.

${ }^{15} \mathrm{O}$ explorador e escritor espanhol (1831 - 1898), autor de diversas publicações sobre a história e a geografia americana, é conhecido principalmente por sua participação na chamada Comissão Científica do Pacífico, promovida pela Espanha entre 1862 e 1865.

${ }^{16}$ Quase nada sabemos sobre Rojas, a não ser que era natural da Península e que foi reitor do Colégio Máximo de Quito (In: CARVAJAL, ALMESTO \& ROJAS, A de. La aventura del Amazonas. Ed. de Rafael Díaz. Madrid: História 16, 1986, p. 27).

${ }^{17}$ Sua primeira impressão foi realizada em Madrid e esteve sob a responsabilidade de Jiménez de la Espada, datando de 1889. Segundo Rafael Díaz Maderuelo, responsável pela edição (1986) que estamos utilizando neste trabalho, ela foi precedida de um importante estudo preliminar que chamava a atenção para a incipiente rivalidade entre jesuítas e franciscanos pela evangelização das populações americanas. Assim é que Frei Laureano de la Cruz, responsável pela expedição da qual resultou a posterior aventura dos leigos franciscanos que chegaram, pelo rio, até Belém, escreveu sobre ela um relato que chamou de "Nuevo descubrimiento del río de Marañón, llamado de las Amazonas, hecho por la Religión de San Francisco año de 1651" (Ver: CARVAJAL, ALMESTO \& ROJAS. La aventura del Amazonas, op. cit., p. 23-24). O uso do termo "Novo Descobrimento" pode ser entendido como uma resposta à pretensão dos jesuítas de Quito de que haveria sido um membro da Ordem, o P. Rafael Ferrer, o primeiro religioso a missionar nas nascentes do rio desde junho de 1602. O manuscrito, transcrito por Díaz Maderuelo, encontra-se conservado na Biblioteca Nacional de Madrid, como uma cópia do original que está na Biblioteca de Paris. Uma impressão em português, como parte da Coleção Brasiliana da Companhia Editora Nacional, foi preparada por C. de Melo Leitão em 1941.
} 
na volta, tomar posse das terras abaixo da região dos omáguas ${ }^{18}$. A expedição contava com 47 canoas, 70 portugueses e quase 2000 índios, entre guerreiros, remadores, mulheres e jovens para serviço.

Capitaneada por Pedro Teixeira, tendo por piloto o português Bento da Costa e como guia o frei Domingos de Brieva, a expedição deixou o Pará em 28 de outubro de 1637 para chegar a Quito dez meses depois de sua partida. Neste intervalo protagonizou o feito de, pela primeira vez, navegar o Amazonas e seu formador, o Napo, contra a correnteza em toda a sua extensão, por mais de 4000 quilômetros. Algumas marcações efetivadas pelo capitão português serviriam para, nas décadas seguintes, sustentar as pretensões portuguesas sobre a região conhecida como "grande omágua" e, desta maneira, alimentar uma polêmica com os espanhóis. Os termos da disputa, embora envolvessem uma questão de limites entre Estados, foram muitas vezes discutidos pelos jesuítas sob Assistência de Espanha que atuavam na área e que viam as incursões portuguesas como um elemento perturbador às suas missões.

Após as festividades protocolares, as autoridades espanholas, igualmente sobressaltadas, determinaram o regresso de Teixeira, cumprindo o itinerário inverso daquele que o conduzira até Quito. Estabeleceram, ainda, que ele fosse acompanhado de observadores encarregados de prestar contas da viagem e relatar dados sobre a geografia, sobre as populações e sobre as possíveis riquezas da região percorrida. O padre Christóbal de Acuña S.J. será especificamente encarregado ${ }^{19}$ pela Audiência de Quito de produzir, para o Conselho das Índias na Espanha, um relatório completo de sua viagem, tendo "particular cuidado em descrever com a maior clareza possível, a distância em léguas, províncias, povoações de índios, rios e lugares específicos que há desde o lugar de

\footnotetext{
${ }^{18}$ Os omáguas formavam o grupo étnico mais populoso e muito temido no grande rio. Habitavam numerosas ilhas e as margens do vale médio do Amazonas. Causaram forte impressão aos primeiros observadores europeus sua pujança econômica (que se traduzia na potencialidade da oferta de alimentos), volume demográfico e potencial guerreiro. Cristóbal de Acuña, por exemplo, atesta sobre a cobiça que despertaram as notícias acerca deles: "Desde as primeiras notícias, insuflaram-se desejos de submeter toda essa região à jurisdição de Quito, pelas multidões de gentios que a povoam" (ACUÑA, Christóbal de. Novo Descobrimento do Grande Rio das Amazonas. Pelo padre Christóbal de Acuña, Religioso da Companhia de Jesus e Qualificador da Suprema Inquisição Geral, ao qual se foi, e se fez por ordem de sua Majestade, no ano de 1639, pela Província de Quito, nos Reinos do Peru. In: ESTEVES, Antônio R. (ed). Novo Descobrimento do Grande Rio das Amazonas. Montevidéu: Consejeria de Educación de Embajada de España en Brasil; Oltaver, 1994, p.129). ${ }^{19}$ Acuña viajou na companhia de José de Artieda, também membro da Sociedade de Jesus.
} 
embarque até a referida cidade e porto do Pará, o informando-vos disso com a maior exatidão (...), para dar a competente notícia de tudo, como testemunho ocular, ao (...) Real Conselho das Índias. (...)”20.

O resultado do cumprimento desta determinação foi "O Novo Descobrimento do rio das Amazonas, pelo padre Christóbal de Acuña, religioso da Companhia de Jesus (...), ao qual foi, e se fez por ordem de Sua Majestade, no ano de 1639, pela Província de Quito, nos Reinos do Peru"21. A obra foi dedicada ao conde-duque de Olivares, o poderoso ministro de Felipe IV, nas mãos de quem o religioso depositava a possibilidade de patrocinar na região "a conversão de infinitas almas, o enriquecimento da Coroa Real e a defesa e proteção de todos os tesouros do Peru"22. Na dedicatória nestes termos apresentada, Acuña sintetiza suas convicções sobre as possibilidades abertas aos espanhóis, a partir do controle efetivo da área, e sustenta o debate sobre os limites entre os dois impérios ao qual nos referimos anteriormente.

Por outro lado, a partir do "Novo Descobrimento" tornava-se muito evidente a disputa entre jesuítas e franciscanos quanto à primazia da comprovação sobre a navegabilidade do rio, ainda que possamos reconhecer que a mesma já estivesse instalada, inclusive repercutindo na escolha de Artieda e Acuña (e não de irmãos da Ordem de São Francisco) como acompanhantes autorizados a seguir com a esquadra portuguesa ao Pará. Segundo Juliana Pedro (2006), o Superior dos franciscanos criticou agudamente supostos manejos políticos que teriam favorecido os jesuítas ${ }^{23}$. Embora religiosos seráficos - os Freis Domingos de Brieva e Augustín de las Chagas, este último como capelão do grupo - tenham acompanhado a expedição ${ }^{24}$, Acuña subtrai estas presenças da

\footnotetext{
${ }^{20}$ PROVISÃO REAL que expediu a Audiência de Quito em nome de Sua Majestade para este Descobrimento. (apud: ESTEVES, Antônio R. (ed). Novo Descobrimento do Grande Rio das Amazonas. Montevidéu: Consejeria de Educación de Embajada de España en Brasil; Oltaver, 1994, p. 18). ${ }^{21}$ ACUÑA, Novo Descobrimento do Grande Rio das Amazonas..., op. cit., p. 35.

${ }^{22}$ Contrariamente ao verificado a respeito da obra de Alonso de Rojas, que, tendo recebido escassa atenção, foi publicada pela primeira vez bastante tardiamente (1880 e 1889), o livro de Acuña alcançou notoriedade, tendo sido editado pela primeira vez em Madrid já no ano 1641. Segundo um especiallista no tema, ela vem a ser a "obra mais importante sobre a Amazônia e seus habitantes, escrita até meados do século XVIII'. PORRO, As Crônicas do rio Amazonas, op. cit., p. 12.

${ }^{23}$ PEDRO. Embates pela memória: narrativas de descoberta nos escritos coloniais da Amazônia Ibérica, op. cit., p. 85-86.

${ }^{24}$ Ver: PEDRO. Embates pela memória: narrativas de descoberta nos escritos coloniais da Amazônia Ibérica, op. cit., p. 88.
} 
sua narrativa, ao mesmo tempo em que se empenha para reforçar a qualidade oficial da sua participação e, desta forma, garantir a autoridade do seu texto.

Seguindo a construção dos argumentos de religiosos das duas Ordens, Juliana Pedro (2006) evidencia o quanto estas escrituras buscavam estabelecer evidências que, não apenas legitimassem o controle espanhol na região, como pudessem marcar, no interior do projeto de colonização, o campo de atuação missionária que cada uma pretendia firmar para si.

Neste espaço de disputa, as questões eram resolvidas no âmbito da escrita. Para uma cultura como a ibérica, que colocava a escrita como sinônima de prova, de documento, de verdade, as disputas eram travadas no âmbito da cultura letrada. Assim, as narrativas da descoberta serviam como elemento de legitimação para a ação colonial, bem como de identificação dos descobridores de espaço de disputa. ${ }^{25}$

Portanto, se estamos efetivamente diante do campo de enunciação de múltiplas vozes e produção de múltiplas versões - de embates pela memória como analisa tão bem a autora -, a escolha dos vocábulos descobrimento ou novo descobrimento remetem ainda à questões muito imediatas que se apresentavam para os religosos. Efetivamente, enquanto no México ou no Peru o clero secular tornou-se proeminente no século XVII, a Amazônia abria-se como uma extensa área de missão para os regulares. Na mesma medida instalava-se a disputa pela primazia e pelo direito ao trabalho de conversão de suas almas.

\section{Sobre as Relaciones}

Quando os jesuítas Alonso de Rojas e Christóbal de Acuña redigiram seus textos, em 1639 e 1641 respectivamente, havia transcorrido um século desde a

${ }^{25}$ PEDRO. Embates pela memória: narrativas de descoberta nos escritos coloniais da Amazônia Ibérica, op. cit., p. 94. 
viagem de Francisco de Orellana sobre a calha do rio e desde a narração desta aventura através das páginas escritas pelo dominicano Gaspar de Carvajal ${ }^{26}$.

As obras de Carvajal, Rojas e Acuña fazem parte de um grupo de textos conhecidos como Relaciones. Ao analisar o conjunto de narrativas que documentam o descobrimento e a conquista da América, Walter Mignolo avalia que estas Relaciones se distinguem das $\operatorname{cartas}^{27}$ e das crônicas, tanto em seus aspectos pragmáticos, quanto nos organizativos ${ }^{28}$. O vocábulo, lembra ele, tinha em espanhol, no século XVI, o sentido de "informe ou narração de algo que ocorreu", correspondente ao relatio e narratio latinos. No contexto dos discursos gerados no ambiente da conquista e colonização da América, ele adquire o significado mais estreito de "relato ou informe solicitado pela Coroa".

Se este aspecto justifica e explica exatamente a natureza do "Novo Descobrimento do rio das Amazonas" de Acuña, o mesmo não pode ser aplicado em sentido estrito aos textos de Carvajal ou ao de Alonso de Rojas. De fato, embora adote o nome de Relación, o documento de Carvajal foi sim escrito como pretenso "informe ou narração de algo que ocorreu", mas numa iniciativa do dominicano, que pretendia isentar Orellana da culpa que lhe era atribuída por não ter cumprido o acordo feito com Gonzalo Pizarro, ao dar seguimento à viagem em vez de voltar em socorro dos companheiros famintos. Assim sendo, a escolha deste tipo discursivo para seu relato

\footnotetext{
${ }^{26}$ CARVAJAL, Gaspar de. Relación que escrebió Fr. Gaspar de Carvajal, Fraile de la Orden de Santo Domingo de Guzmán, del nuevo descubrimiento del famoso Rio Grande que Descubrio por muy gran ventura el Capitán Francisco de Orellana desde su nacimiento hasta salir a la mar, con cincuenta y siete hombres que trajo consigo y se echo a su ventura por el dicho rio, y por el nombre del capitan que le descubrio se llamo el Rio de Orellana (1540). In: CARVAJAL, ALMESTO \& ROJAS, A de. La aventura del Amazonas. Ed. de Rafael Díaz. Madrid: História 16, 1986 (Crônicas de América 19).

${ }^{27}$ Ao lado de outros textos, as Cartas de Hernán Cortez compõem, para Beatriz Pastor (1988), o que a autora chama de "discursos narrativos da conquista". As diversas vozes contidas nesta expressão veiculam-se, para ela, sob três formas principais: o "discurso mitificador", que opera uma ficcionalização tanto da realidade do Novo Mundo quanto da natureza e do significado do processo de conquista, o "discurso de desmitificação" (discurso narrativo do fracasso), que questiona os modelos formulados pelo primeiro deles, e o "discurso narrativo da rebelião", que estuda o processo de crise e liquidação simbólica dos mitos e modelos anteriores.

${ }^{28}$ MIGÑOLO, Walter D. Cartas, crónicas y relaciones del descubrimiento y de la conquista, op. cit., p.70.
} 
(Relación que escrebió Fr. Gaspar de Carvajal), possivelmente aspire conferir a ele uma garantia de veracidade. Nas suas próprias palavras:

Yo Fray Gaspar de Carvajal, el menor de los religiosos de la Orden de (...) Santo Domingo, he querido tomar este poco trabajo y suceso de nuestro camino y navegación, así para decirla y notificar la verdade en todo ello, como para quitar ocasiones a muchos que quieran contar esta nuestra peregrinación o al revés de cómo lo hemos pasado y visto; y es verdad en todo (lo) que yo he escrito y contado. ${ }^{29}$

Por sua vez, embora adote para seu texto o nome de "Relación del descubrimiento del Rio de las Amazonas ...", Rojas, a quem se atribui sua autoria, não participou diretamente, como testemunha autorizada dos fatos que relata. Podemos assim indagar sobre os motivos que determinaram tal eleição.

A solicitação do testemunho e registro escrito das ações de descobrimento e conquista fazia parte do repertório de práticas pelas quais os espanhóis buscavam assegurar a primazia e legimitidade de suas iniciativas. Era também um expediente da Monarquia para - na medida do possível - acompanhá-las e controlá-las. Dada a condição especial da região amazônica nesta oportunidade ${ }^{30}$, área de litígio colocada entre os interesses dos Impérios Luso e Espanhol, Rojas preocupa-se em inventariar o espaço, indicar as possibilidades de seu aproveitamento e assinalar pontos vulneráveis à ação de inimigos dos castelhanos. A escolha da Relação como estratégia narrativa pode assim estar associada ao caráter estratégico que imprimiu em várias de suas observações.

Efetivamente, como gênero, a relação apresentava-se como um ponto de convergência entre a epístola e o documento legal. Assim como as cartas, ela narrava e informava múltiplos aspectos da realidade, descrevia e comentava ações e comportamentos; incluía reflexões do autor e daqueles que o rodeavam. Como documento legal, se comprometia com a veracidade do narrado: "El concepto de carta de relación llevaba implicita la certificacion del contenido y constituía uma cierta garantía de su veracidad"31. A escrita nos moldes deste tipo discursivo deveria ser

\footnotetext{
${ }^{29}$ CARVAJAL, Relación que escrebió Fr. Gaspar de Carvajal..., op. cit., p. 98

${ }^{30}$ Vésperas da Restauração Portuguesa.

${ }^{31}$ PASTOR, Beatriz. Discursos narrativos de la conquista: mitificación y emergencia. Hanover: Ediciones del Norte, 1988, p. 95.
} 
penhor de objetividade e da natureza documental do testemunho, avalizando a veracidade e imparcialidade da mensagem que portava. A esta garantia implícita da natureza veraz indicada na utilização da forma oficial de Relação, costumava estar associada, ainda, a utilização recorrente do termo "verdadeira".

Acuña, por exemplo, afirma estar ciente da tensão que se pode estabelecer entre a novidade que se apresenta à observação $0^{32}$ e o descrédito ${ }^{33}$ diante da grandiosidade que ela porta. Por isto, acrescenta logo no início do seu texto algumas certificações que deveriam afiançar sua veridicidade: de Pedro Teixeira, capitão da expediçãa $0^{34}$, e do Frei Pedro de Santa María y de la Rúa, Comissário Geral dos Mercedários no Maranhão e Pará ${ }^{35}$. A Relación de Rojas, por sua vez, vai antecedida de Carta de D. Martín de Saavedra y Guzmán, governador e capitão geral de Nova Granada. Mais ainda, o fazer relación costumava estar associado à observação direta como base necessária dos conhecimentos e informações reportados no documento. Ou seja: o testemunhalismo ${ }^{36}$ funciona à guiza de autorização de verdade do narrado, elemento comum em boa parte das crônicas do período.

Lembra Walter Mignolo (1982) ainda que, uma das principais características das relações é que elas não são o registro de uma observação livre de quem escreve, senão que respondem a pedidos oficiais, como está explicitado na obra de Acuña. Tal situação fica especialmente formalizada desde 1574 em que se codificam as perguntas a serem atendidas nas informações escritas.

\footnotetext{
32 “... um novo mundo, nações novas, reinos novos, ocupações novas, modo de viver novo e, resumindo-o em uma só palavra, um rio de água doce navegado por mais de mil e trezentas léguas desde seu nascimento até seu fim, todo pleno de novidades" (ACUÑA, Novo Descobrimento do Grande Rio das Amazonas..., op. cit., p. 39).

33 "Desejando, então, trazer à vista de todos o novo descobrimento do Grande Rio das Amazonas (...) e temendo (...) sofrer receios quanto a sua veracidade, quis assegurar-lhe caro leitor, uma e outra coisa" (Idem, p. 39).

34 "Pedro Teixeira, no presente CAPITÃO-MOR (...) certifico e afirmo sob juramento, pelos Santos Evangelhos, que é verdade ...” (Idem, p. 41).

35 “De tudo isto posso dar fé, como testenha ocular de toda a jornada que fizemos juntos ..." (Idem, p. 45).

${ }^{36}$ Pastor informa que, para Bernal Díaz del Castillo e Bartolomeu da Las Casas, existiam duas formas de narrar a Conquista: como testemunha presencial de uma ação em que se pode ou não ter participado, mas que se conhece de primeira mão, ou como recompilador e narrador de relatos de eventos dos quais o conhecimento é secundário. Este seria o caso de Lopes de Gomara a quem Bernal Díaz del Castillho desautorizou como cronista da conquista do México, justamente por isto (PASTOR, Discursos narrativos de la conquista: mitificación y emergencia, op. cit., p. 97).
} 
Entretanto, enquanto as cartas e crônicas seguiam uma certa tradição discursiva, sendo modelos clássicos de escrita, as relações atendiam aos imperativos do momento específico da Conquista, baseando-se nas necessidades de informações que se aplicam sobre certas circunstâncias e lugares. Justamente por isto, o conjunto de questões que elas deveriam abordar sofre constantes ajustes e transformações, situação que não impede, contudo, que possamos distinguir um repertório de dados que deveriam compor o relato. Entre eles estão: o nome das províncias reconhecidas e de suas populações; seus primeiros descobridores e conquistadores; o ano do descobrimento; as características da geografia e do clima; a existência de minas de metais, pedras preciosas ou bancos de perólas, etc. ${ }^{37}$

A utilização deste tipo discursivo inscrevia a narrativa que ele abrigava em um marco oficial e documental, propondo uma equivalência entre narração e verdade. ${ }^{38}$ Forjadas na necessidade do momento, as relaciónes, como tipo discursivo, deviam, portanto, recolher e ordenar informações sobre as novas terras e povos conquistados. A atenção a esta injunção efetivamente singularizou alguns dos textos aqui em análise.

\section{Descobrir e Redescobrir a Amazônia:}

Ao final do século XVII, mais especificamente em 1691 e 1698 respectivamente, dois importantes novos textos sobre a Amazônia, escritos sob a responsabilidade dos padres Samuel Fritz e João Felipe Bettendorf ${ }^{39}$, ambos jesuítas em trabalho de missão na área, revelam o quanto a orla do rio encontrava-se, então, profundamente transformada. Eles dão a perceber, por exemplo, a drástica e irretornável diminuição das populações ribeirinhas ocorrida à medida que a várzea amazônica fora sendo devassada. Ao relatar sua viagem pelo rio, regressando de Belém para Maynas, o $\mathrm{P}^{\mathrm{e}}$. Fritz descreve sucessivas aldeias desertas que encontra pelo caminho, em virtude das agressões sofridas de parte dos europeus, das guerras inter-tribais que se acirraram ou da fuga de suas populações para regiões menos

\footnotetext{
${ }^{37}$ Ver: MIGÑOLO. Cartas, crónicas y relaciones del descubrimiento y de la conquista, $o p$. cit., p. 71 a 85.

${ }^{38}$ PASTOR, Discursos narrativos de la conquista: mitificación y emergencia, op. cit., p. 148. ${ }^{39}$ FRITZ, Samuel. Diario del Padre Fritz [1691]. Edición de Hernán Rodriguez Castelo, s/l, 1997, e BETTENDORFF, João Felipe [1698]. Crônica da Missão dos Padres da Companhia de Jesus no Estado do Maranhão. s/l, 1910.
} 
inseguras. Desta forma, na crônica de Bettendorf já quase não há notícias das grandes nações ou províncias descritas nos textos mais antigos. Segundo Porro (1993), nesta oportunidade elas já não se impunham, como entidades singulares, à curiosidade dos europeus.

Por outro lado, percebe-se que, embora realizada sem grandes contingentes humanos, a irradiação portuguesa neste espaço era um dado concreto. Faziam parte deste movimento tanto as tropas de resgate e os grupos de exploradores a procura de drogas do sertão, como religiosos em busca de indígenas para serem nucleados e catequizados, autoridades civis e militares.

Esta situação havia sido uma das principais preocupações ressaltadas por Cristóbal de Acuña ao longo de toda Relación que escreveu. Duas idéias principais atravessam o texto: a necessidade de ocupação urgente e efetiva do território por parte da Espanha, a fim de deter o avanço português, tanto quanto a de aumentar a presença de religiosos que atuassem na catequese dos grupos indígenas. Ambas as preocupações aparecem freqüentemente associadas, como quando o jesuíta critica duramente as estratégias empregadas pelos luso-brasileiros para cativar escravos índios por meio da "guerra justa":

Tal coisa costumam fazer os portugueses entre os gentios, não com tão bom zelo como a ação demonstra em si, servindo-lhes o santo madeiro da cruz, levantado em alto título e capa, para disfarçar suas maiores injustiças, como a contínua escravização dos (...) índios que (...) são levados em rebanhos a suas propriedades, para vender alguns deles e servir-se com todo o rigor dos outros. ${ }^{40}$

Embora a reiteração destas idéias esteja presente em toda obra, elas serão especialmente sistematizadas no Memorial $^{41}$ que acompanha a Relación. Nele, Acuña apresenta uma série de argumentos através dos quais prentende sensibilizar as autoridades espanholas sobre suas convicções. Sugere ele que, se aos poderes metropolitanos cabiam as medidas em favor do controle político-ad-

\footnotetext{
${ }^{40}$ ACUÑA, Novo Descobrimento do Grande Rio das Amazonas..., op. cit., p. 113.

${ }^{41}$ MEMORIAL PRESENTADO EN EL REAL CONSEJO DE LAS INDIAS SOBRE EL DICHO DESCUBRIMIENTO DESPUÉS DE LA REBELIÓN DE PORTUGAL, que ocupa as páginas 200 a 210 da presente edição.
} 
ministrativo do território ${ }^{42}$, aos religiosos da Companhia poderia ser atribuído o trabalho de sua "conquista espiritual". Acuña defende a primazia e o direito dos jesuítas, que "há anos cultivam com sua doutrina, os principais cursos desta nova conquista", e solicita recursos humanos que permitam dar continuidade ao trabalho. Sua obra, da mesma forma que aquela atribuída ao também jesuíta Alonso de Rojas, está claramente inserida na disputa entre a Companhia de Jesus e a Ordem dos Franciscanos pela Amazônia como espaço de missionação.

Ele não apenas insinua o fato na própria denominação que lhe atribui - " $O$ Novo Descobrimento" -, como, em um dos parágrafos iniciais do texto, insere a entrada dos franciscanos em missão no Amazonas ${ }^{43}$, no esforço de "prosseguir a obra de descobrimento deste rio, que fazia mais de trinta anos os padres da Companhia de Jesus tinham começado pela região dos Cofanes, onde os nativos mataram cruelmente o Padre Rafael Ferrer, como pagamento à boa doutrina que lhe ensinava" ${ }^{\prime 4}$. As disputas entre as Ordens pela precedência na área e os direitos à ela associados quanto à catequese dos nativos - inclusive a partir da constituição de uma memória escrita a este respeito por franciscanos e jesuítas - guardam, desse modo, outra acepção para a noção "descobrir e redescobrir" o Amazonas a partir destes textos ${ }^{45}$.

Sem deixar de afirmar os benefícios religiosos advindos do estabelecimento da autoridade castelhana sobre a região (a conversão dos nativos em que ele parece não confiar que os luso-brasileiros fossem investir ), Acuña insiste em questões políticas e estratégicas, o que está de acordo com a natureza formal do texto. Entre estas estavam o definitivo controle de uma região que a Coroa Castelhana pretendia ser sua ${ }^{46}$, a proteção aos tesouros do $\mathrm{Peru}^{47}$ diante de uma

\footnotetext{
${ }^{42}$ Acuña sugere que a posse do território poderia ser levada a efeito sem ônus da Coroa, valendo-se apenas das "muitas pessoas que, a sua própria custa oferecem-se para fazer estas conquistas, unicamente pelos beneficios que dela se pode ter, como as encomendas dos índios, a repartição de terras, a provisão de ofícios e outros similares" (ACUÑA, Novo Descobrimento do Grande Rio das Amazonas..., op. cit., p. 201)

43 1635/1636 e 1637.

${ }^{44}$ ACUÑA, Novo Descobrimento do Grande Rio das Amazonas..., op. cit., p. 41.

${ }^{45} \mathrm{O}$ tema é debatido em recente dissertação de mestrado. Ver: PEDRO. Embates pela memória: narrativas de descoberta nos escritos coloniais da Amazônia Ibérica, op cit.

${ }^{46}$ Afirmada, por exemplo, a partir da concessão a Orellana, em 13 de fevereiro de 1544, de uma Capitulação concedendo-lhe 200 léguas a oeste da desembocadura do rio.

${ }^{47} \mathrm{O}$ controle do território evitaria ainda que as nações inimigas (holandeses), auxiliadas pelos portugueses (de cuja lealdade ele desconfia), pudessem chegar até as ricas regiões do Peru e da Nova Granada.
} 
possível rota alternativa ilícita, o impedimento das atividades comerciais portuguesas com os peruanos e mesmo a substituição, em favor do Amazonas, dos caminhos mais perigosos, caros e difíceis através dos portos do Panamá e Cartagena. A submissão das várias nações indígenas que ocupam o rio, permitiria expulsar da sua foz quaisquer inimigos estabelecidos ilicitamente, pondose "freio e se castigando o mal visto atrevimento dos portugueses" 48 .

Em mais de uma oportunidade, o jesuíta condena as ações de apresamento feitas pelos portugueses. Ele não apenas critica a cobiça com que se lançam à busca de escravos, como o tratamento dispensado aos presos e o desrespeito às mulheres, chegando mesmo a denunciar a hipocrisia que se escondia sob a fórmula legal da "guerra justa":

E que ninguém diga que o fato destes índios não quererem vender seus escravos seja porque os têm para comê-los em suas bebedeiras, como dizem sem fundamento os portugueses, que andam metidos neste negócio e com isto querem encobrir sua injustiça. (...) O que quero convencer é de que não existem em todo este rio açougues públicos onde o ano todo se pesa carne de índios, como propalam aqueles que, argumentando querer evitar semelhante crueldade, praticam crueldades ainda maiores, transformando com seus rigores e ameaças, em escravos aqueles que não o são. ${ }^{49}$

Mais ao final do século será a vez do já referido Padre Samuel Fritz ${ }^{50}$, missionário entre os omáguas, questionar o direito a que se atribuíam os portugueses ao território destes índios no Rio $\mathrm{Napo}^{51}$ e registrar, impotente, a ameaça que representavam ao empreendimento da Companhia em toda a província:

\footnotetext{
${ }^{48}$ ACUÑA, Novo Descobrimento do Grande Rio das Amazonas..., op. cit., p. 207.

${ }^{49}$ ACUÑA, Novo Descobrimento do Grande Rio das Amazonas..., op. cit., p 137.

${ }^{50}$ Nascido na Boêmia entre 1650 e 1656, entrou para a Ordem dos jesuítas em 1673, vindo para a América para atuar na Província de Quito em 1684. Tornou-se o Superior da Missão de Mainas em 1704, vindo a morrer em março de 1725. Além do "Diário" (1689 - 1723), em que registra seu trabalho apostólico e que foi publicado pela primeira vez em 1889 como parte de uma obra maior, Fritz elaborou, ainda, notável e afamado mapa resultante de suas constantes viagens pelo Amazonas.

${ }^{51} \mathrm{O}$ qual se fundava em um marco de madeira (um tronco de árvore) que, durante a viagem de Pedro Teixeira no retorno de Quito à Belém, os luso-brasileiros usaram como referencial simbólico de sua tomada de posse da região em nome da coroa de Portugal.
} 
Los portugueses, despues que partieron, fueron á Guapapaté, un día rio abajo, y enfrente de la aldea se detuvieron diez dias tirando allí en tierra firme zarzaparilla. También hicierón allí (...) un desmonte (...) deciendo que allá habían de venir à poblarse, y no dudo que así lo haran, por lo mucho que codiciam por esclavos los indios de acá arriba; á más que discurren que por acá han de hallar puerta para entrar al Dorado, que sueñan no estar muy distante. ${ }^{52}$

Devemos lembrar de fato que, para além das tradicionais rivalidades das coroas ibéricas em seus territórios coloniais americanos, a ação dos luso-brasileiros, especialmente dos preadores de escravos índios, era um tema sensível aos jesuítas. Neste mesmo momento, o embaralhamento das fronteiras decorrente da União Ibérica facilitara as razias dos paulistas contra os índios aldeados pelos jesuítas ao sul, especialmente nas famosas reduções do Guairá, Tape e Itatim $^{53}$. As aldeias sofriam repetidos ataques, os quais praticamente inviabilizaram a ação dos missionários na margem oriental do rio Uruguai, obrigandoos, inclusive, a transmigrar um grande número de índios para áreas mais distantes e abrigadas.

Entre argumentos levantados por Acuña em defesa da ocupação espanhola do território amazônico, possivelmente o mais delicado seja aquele que trata da relação com as sociedades indígenas. Ele acusa o despovoamento de vastas regiões sob domínio espanhol, especialmente daquelas "em que há minas ou outras propriedades de importância que dependem de seu trabalho pessoal", prejudicando as extração de riquezas a elas associadas ${ }^{54}$. A conquista de novas terras e a conversão de novas gentes seria o remédio para este perigo, com o que sugere que as populações amazônicas, convertidas, pudessem repovoar o Peru:

Se eles se sujeitarem ao Santo Evangelho, com a paz geral cessarão as contínuas guerras em que a cada dia se consomem uns aos outros e aumenta-

\footnotetext{
${ }^{52}$ FRITZ. Diario del Padre Fritz [1691], op. cit., p. 95-96.

${ }^{53}$ Ver, por exemplo: MONTOYA, Antonio Ruiz de. Conquista Espiritual. Hecha por los Religiosos de la Compañía de Jesus en las províncias de Paraguay, Parana, Uruguay y Tape. (1639) Estudio preliminar y notas Dr. Ernesto J. A. Maeder. Rosario: Equipo Difusor de Estudios de Historia Iberoamericana, 1989.
}

${ }^{54}$ ACUÑA, Novo Descobrimento do Grande Rio das Amazonas..., op. cit., p. 207. 
rão tanto, de tal maneira que, rompendo por insuficientes, os limites atuais, será necessário avançar por muitos mais espaçosos reinos. E como só com eles se beneficiarão as muitas minas e demais vantagens que em suas nações oferece a fertilidade da terra, deve-se como outro novo Peru, aceitar logo sua conquista, principalmente com a facilidade que aqui se oferece..$^{55}$

Não resta dúvida de que suas observações dizem respeito ao quadro de aguda depressão demográfica das Índias de Castela nesta centúria, bem como de severa depressão econômica do próprio Reino. Aliás, algumas Declarações que antecedem e acompanham a "Relación del Descubrimiento del Río de las Amazonas" escrita por Alonso de Rojas S.J. também punham de relevo esta questão. Efetivamente, o Presidente da Audiência e Capitão-Geral do ViceReino de Nova Granada, D. Martín de Saavedra y Guzmán, escrevia à Monarquia em 29 de maio de 1639 advertindo sobre a fragilidade do controle espanhol sobre o território e sobre os ganhos advindos em preservá-la, haja vista "el estado presente la conservación y que se reparen los daños que el tiempo y menoscabo de los indios van causando y la naturaleza de los españoles que pasan a estos reinos, así en los gastos que hacen como en lo poco que traballan para ellos, y la falta de armas y municiones que se experimenta" ${ }^{56}$.

Acusando a pouca atenção e cuidado que a região vinha merecendo por parte das autoridades espanholas, os dois jesuítas exaltam a sua potencialidade:

Este es el famoso río de las Amazonas que corre y baña las más fértiles y pobladas tierras que tiene el imperio del Perú, y sin usar de hipérboles, lo podemos calificar por el mayor y más célebre río del orbe (...) [que] riega los más extendidos reinos, fecunda más vegas, sustenta más hombres, aumenta con sus aguas a más caudalosos oceanos. (...) arenas de oro tiene, tierras riega que atesoran innumerables riquezas (...). Del río

\footnotetext{
${ }^{55}$ Idem, p. 207.

${ }^{56}$ ROJAS, Alonso de. Relación del Descubrimiento del Rio de las Amazonas y sus dilatadas Províncias y Relación del Descubrimiento del río de las Amazonas, hoy San Francisco de Quito, y declaración del mapa onde está pintado... (1640). In: CARVAJAL, ALMESTO \& ROJAS, A de. La aventura del Amazonas. Ed. de Rafael Díaz. Madrid: História 16, 1986 (Crônicas de América 19), p. 229.
} 
de las Amazonas afirman los que le han descubierto, que sus campos parecen paraísos y sus islas jardines, $\ldots{ }^{57}$

Acuña qualifica a região como um "novo Peru", afirmando que estaria entre as mais ricas, férteis e povoadas do Vice-Reino. Atesta que ela é rica em metais preciosos e, embora admita que não os tenha visto em quantidade, sustenta seu argumento em informações recebidas dos indígenas, como a das minas de ouro dos yorimáns nas proximidades do Tapajós ou do rio Genipape que "sozinho deixa atrás com seus tesouros aos maiores de todo Peru" 58 . Além do mais, como ao Amazonas "rendem vassalagem e pagam tributo" inúmeros rios provenientes de áreas muito ricas em metais, era de se crer que ele também os guardasse.

Não me refiro às muitas minas de ouro e prata de que se tem notícia, já descobertas e que se descobrirão forçosamente (...) e que (...) serão em maior número e mais ricas que todas do Peru (...). E não digo isto à toa, sem fundamento, levado apenas (...) pelo entusiasmo que mostro ao engrandecer este Rio, mas baseado na razão e na experiêcia. Esta eu tive do ouro que encontramos com alguns índios deste Rio. ${ }^{59}$

Mas a região não era rica apenas em prata, ouro e pedras preciosas, como apresentava ainda uma natureza que Acuña não se cansa em exaltar. Madeiras nobres permititiriam a construção de barcos, plantas medicinais, peixes, aves e frutas diversas ofereciam-se como dádivas a serem colhidas. O clima aprazível e as terras favoráveis, aceitariam o cultivo de tabaco, cacau e cana-de açúcar, excelentes itens de exportação ${ }^{60}$.

A estas condições favoráveis, ele agrega aquela que seria, de fato, a maior riqueza da região e o ponto de interesse primeiro do religioso: o grande número de indígenas que viviam nas margens do rio e de seus afluentes, e que deveria ser alvo da ação missionária.

${ }^{57}$ Idem, p. 234-235.

${ }^{58}$ ACUÑA, Novo Descobrimento do Grande Rio das Amazonas..., op. cit., p. 189.

${ }^{59}$ Idem, p. 103.

${ }^{60}$ Numa afirmação de difícil credibilidade, ele disse ter testemunhado, em uma área mais ou menos 100 léguas distante da provícia dos omáguas, dias de frio tão intenso (o qual, segundo os nativos, durava pelos meses de junho, julho e agosto) que seria possível nelas obter trigo e "todos os demais grãos e frutas" que se produzem em Quito. (Idem, p. 139), 


\section{4 - Uma infinidade de gente e de diferentes nações:}

Como vimos, as Relaciones deveriam obedecer a uma estrutura formalmente definida, que determinava o que e como devia ser objeto de interesse. Apesar disto, podemos perceber, em alguns momentos, que o ato de escrever tomava em conta um duplo referencial: o da realidade vivida, que autoriza os sujeitos do discurso a afirmar a verdade de suas anotações, e o corpo integrado pelo conjunto de obras anteriores, com os quais inclusive dialogam.

O Novo Descobrimento, desta forma, dialoga várias vezes com as obras anteriores de Carvajal e de Rojas ${ }^{61}$. Quanto à Relação do dominicano, ele reitera, por exemplo, as afirmações que, um século antes, testemunhavam a densidade populacional da várzea e o tamanho dos povoados que se distribuíam ao longo dela. Realmente, o registro da navegação de Orellana e seus homens pelo rio descrevia longas extensões ocupadas por aldeias às vezes muito próximas umas das outras, algumas delas grandes, aparentemente sedentárias e auto-suficientes, protegidas por conjuntos de guerreiros e lideradas por senhores poderosos.

Apesar da redução da população indígena ao longo do primeiro século de colonização, provavelmente ainda não tão drástica como em outras regiões do Novo Mundo, em 1641 era a vez do jesuíta testemunhar a presença de uma considerável densidade demográfica na várzea amazônica.

Todo este novo mundo (...) está habitado por bárbaros de variadas províncias e nações, das quais posso dar boa fé enumerando-as por seus nomes e indicando sua localização, algumas de vista e outra por informações de índios que nelas estiveram, passam de cento e cinquenta, (...) tão extensas e tão ocupadas por moradores como a que vimos por todo o trajeto, (....) Tão seguidas estão umas das outras que, dos últimos povoados de uma, em muitos casos se pode ouvir lavrar a madeira na outra ... ${ }^{62}$

\footnotetext{
${ }^{61}$ Acuña chega mesmo a copiar extensas passagens do "Descubrimiento del rio de las Amazonas", condição que serviu para sustentar a atribuição de autoria de Alonso de Rojas para o manuscrito originalmente anônimo. Ou seja: o fato de os dois autores pertencerem à Companhia de Jesus teria permitido a Acuña valer-se, desta forma, do texto de um irmão de Ordem. ${ }^{62}$ Idem, p. 106.
} 
De outro lado, ao contrário da experiência de Orellana e de seus homens, fustigados constantemente por grupos hostis ${ }^{63}$, Acuña refere-se ao fato de que, embora os índios fossem belicosos e cheios de brio e vivessem em estado de constante conflitividade uns com os outros, "nenhum tem para com o espanhol atitude hostil, como se notou em toda viagem, na qual nenhum bárbaro jamais se atreveu a usar contra nós, outra defesa do que daquela que usam os covardes prevenidos que é a fuga" ${ }^{\circ 4}$. A constatação pode refletir que a experiência ensinara aos povos da região sobre a dificuldade em dar combate aos europeus e que a retirada era a melhor estratégia a ser adotada ${ }^{65}$.

As apreciações de Acuña sobre os indígenas são costumeiramente favoráveis; é gente pacífica, de boa índole e adaptada ao ambiente em que vivem com fartura e bonança. Tal como se esperava de um texto da natureza de uma $R e$ lación, o autor apresenta uma rica quantidade de informações sobre eles, informações estas cuja importância cresce na medida em que muitos destes grupos vieram a desaparecer fisicamente nas décadas seguintes. Entre outras coisas foram objeto de sua atenção: as armas que usavam (não só contra os inimigos, mas também para obterem alimentos), os procedimentos para fazerem suas bebidas, as ferramentas que empregavam, bem como práticas de pesca e aprisionamento de tartarugas em armadilhas. $\mathrm{O}$ texto informa ainda sobre as redes de trocas que se estabelecem pela água entre várias aldeias, incluindo não só bens de prestígio, como bens de uso, como a cerâmica ou os tecidos. ${ }^{66}$

\footnotetext{
${ }^{63}$ No caminho para a aldeia de Machiparo, por exemplo, e "antes que llegásemos a este pueblo (...) vimos estar blanqueando los pueblos (...) cuando vimos venir por el río arriba gran cantidad de canoas, todas puestas a punto de guerra (...). Traían muy gran grita, tocando muchos atambores y trompetas (...) y amenazandonos que nos habían de comer. (...) los indios se venían acercando (...) y así venían tan ordenadamente y con tanta soberbia, que parecía ya que nos tenían en las manos" (CARVAJAL, Relación que escrebió Fr. Gaspar de Carvajal..., op. cit., p. 60-61).

${ }^{64}$ ACUÑA, Novo Descobrimento do Grande Rio das Amazonas..., op. cit., p. 106.

65 “Encontrávamos estas aldeias, em sua maioria, sem seus habitantes pois, com as notícias falsas de que vínhamos destruindo, matando e escravizando, quase todos haviam se retirado para os montes ..." (Idem, p.145).

${ }^{66}$ Interessante observar que, a este respeito, Acuña utilize-se não apenas de um referencial europeu para criar uma imagem da situação, mas também daquele das cidades do planalto mexicano: "Todos os que vivem às margens deste grande rio estão reunidos em grandes povoações e, como os venezianos ou mexicanos, todas as suas relações são feitas por água, em embarcações pequenas, que se chamam canoas" (Idem, p. 106).
} 
Igualmente importantes são as informações que saem do âmbito da cultura material, como aquelas sobre ritos de hospitalidade, práticas funerárias, "ídolos" e "feiticeiros". Embora ele reconheça "malícia" nas ações dos seus "feiticeiros", não encontramos em seu texto as fortes adjetivações e mesmo a demonização dos sacerdotes nativos, de certa forma freqüentes na pena dos jesuítas. O sacerdote revela-se mesmo um observador muito sensível ao tratar, por exemplo, do "uso dos escravos que cativam", percebendo que seu valor era outro que não apenas o econômico e que as relações travadas neste particular diferiam daquelas conhecidas no Ocidente ${ }^{67}$.

A relativa objetividade da narrativa de Acuña, muito interessado em repertoriar informações precisas sobre a geografia e a potencialidade econômica do território, encontra seu limite, todavia, no que se refere a alguns temas que foram freqüentes nas mais diversas classes de discursos sobre o descobrimento e a conquista da região. Neste particular o corpo de informações elaboradas desde a viagem de Carvajal retorna fazendo confluir o desejo e a fantasia dos espanhóis com lendas e mitos gestados neste ambiente e, ao que parece, alimentados pelos índios. O desconhecimento ou o conhecimento parcial a partir de uma dada época, a comunicação truncada e os equívocos de interpretação, tornavam fácil aos aventureiros e sonhadores situar em regiões inexploradas vários mitos das tradições ocidental e indígena combinados. E se não fosse o suficiente, este repertório duplo foi enriquecido pelos relatos fantásticos gestados e transmitidos, por europeus e nativos ${ }^{68}$ ao longo de todo o processo de exploração e conquista nesta "zona de contato", cruzando saberes e experiências de sujeitos até então separados por descontinuidades históricas e geográficas (PRATT, 1999).

\footnotetext{
${ }^{67}$ Referindo-se aos omáguas diz que "dos escravos que (...) cativam em suas batalhas, servem-se para tudo o que for necessário, tendo-lhes tanta afeição que comem no mesmo prato. Tentar fazer com que os vendam é algo que sentem muito, (...). Compravam-se deles panos, tecidos e lavrados, que com boa vontade davam. Tratava-se da venda de canoas, que são os cavalos ligeiros nos quais andam, e eles rapidamente estavam de acordo. Mas, ao falar-lhes dos escravos, e apertando-os para que os vendessem, surgia o descompadrar-se, o entristecer-se, (...) mostras evidentes de que (...) mais sentem em vendê-los que com desfazer-se de tudo o mais que possuem (CARVAJAL, Relación que escrebió Fr. Gaspar de Carvajal..., op. cit., p. 136 - 137).

${ }^{68}$ Este processo, pelo qual os americanos participam do que chamou da "reinvenção da América" no contexto das viagens do final do XVIII e do XIX, Pratt (1999) denominou de "transculturação".
} 
É mesmo extraordinária a vitalidade de tradições como a das Amazonas ou do Lago Dourado, reafirmadas sempre, mesmo quando uma série de experiências negativas e fracassos em localizá-las objetivamente poderiam ter feito arrefecer a compreensão de sua existência. Assim, Pastor (1988) avalia que o fracasso em encontrar a "fonte da eterna juventude" ou as "sete cidades de Cíbola”, por parte das expedições enviadas à América do Norte, não haviam sido suficientes para anular o impulso mitificador de uma coletividade que transferiu, de um hemisfério a outro, não os mitos (com exceção do das amazonas), mas a mitificação da nova realidade inexplorada.

Desta forma, enquanto a experiência dos que acompanharam o capitão Orellana foi marcada pelo medo, pela fome e pelo desespero ${ }^{69}$, Alonso de Rojas e Cristóbal de Acuña puderam elaborar imagens próximas a um paraíso terrenal, a um jardim das delícias. Especialmente em Acuña, a perturbação a este estado próximo do edênico quase nunca é causada pelas condições naturais ("se não houvesse a praga dos mosquitos, poder-se-ía dizer (...) tratar-se de um imenso paraíso") ou pelos nativos. Ao contrário é a colonização que irrompe com sua carga de desorganização e violência.

Na época, como agora, sobre a Amazônia alternam-se, pois, as noções de natureza pródiga, riqueza e variedade de recursos que permitem fartura e abundância, com a de terreno hostil, não cultivado, vasto e ameaçador. Novos inventários, produzidos ao longo dos séculos seguintes, especialmente à medida que a região se apresentar como alvo da atenção dos naturalistas, vão contribuir para a constituição do repertório de símbolos e imagens pelo qual habitualmente pensamos sobre ela. Elaborados na "zona de contato", estes novos textos, produzidos a partir de referenciais cognitivos (o discurso científico) diferenciados daqueles que se constituíram em matéria de exame neste trabalho, não foram, todavia, suficientes para cancelar completamente o referente imaginário que articulou à representação da Amazônia desde o tempo do seu descobrimento.

\footnotetext{
${ }^{69}$ Tendo sido ainda mais dramática, pela violência em meio a qual se produziu, aquela dos homens que acompanharam o grupo de Pedro de Ursúa e Lope de Aguirre em 1561.
} 


\section{Referências Bibliográficas}

ACUÑA, Christóbal de. Novo Descobrimento do Grande Rio das Amazonas. Pelo padre Christóbal de Acuña, Religioso da Companhia de Jesus e Qualificador da Suprema Inquisição Geral, ao qual se foi, e se fez por ordem de sua Majestade, no ano de 1639, pela Província de Quito, nos Reinos do Peru. In: ESTEVES, Antônio R. (ed). Novo Descobrimento do Grande Rio das Amazonas. Montevidéu: Consejeria de Educación de Embajada de España en Brasil; Oltaver, 1994.

ALMESTO, Pedro de. Relación verdadera de todo lo que sucedió en la jornada de Omagua y Dorado que el governador Pedro de Horsua se fue a descubrir desde el Pirú por un río que llaman de las Amazonas ... tratáse ansi mismo del alzamiento de Don Fernando de Guimarán y Lope de Aguirre (1559). In: CARVAJAL, ALMESTO \& ROJAS, A de. La aventura del Amazonas. Ed. de Rafael Díaz. Madrid: História 16, 1986 (Crónicas de América 19).

BETTENDORFF, João Felipe [1698]. Crônica da Missão dos Padres da Companhia de Jesus no Estado do Maranhão. s/l, 1910.

CARVAJAL, Gaspar de. Relación que escrebió Fr. Gaspar de Carvajal, Fraile de la Orden de Santo Domingo de Guzmán, del nuevo descubrimiento del famoso Rio Grande que Descubrio por muy gran ventura el Capitán Francisco de Orellana desde su nacimiento hasta salir a la mar, con cincuenta y siete hombres que trajo consigo y se echo a su ventura por el dicho rio, y por el nombre del capitan que le descubrio se llamo el Rio de Orellana. In: CARVAJAL, ALMESTO \& ROJAS, A de. La aventura del Amazonas. Ed. de Rafael Díaz. Madrid: História 16, 1986 (Crónicas de América 19).

CUNHA, Manuela Carneiro da. Introdução a uma história indígema. In: CUNHA, Manuela Carneiro da (org.). História dos índios do Brasil. São Paulo: Cia das Letras, Secretaria Municipal de Cultura: FAPESP, 1992, p. 09 - 24.

DANIEL, João. Tesouro Descoberto no Máximo Rio das Amazonas. Rio de Janeiro: Contraponto, 2004.

DOWNES, Peter. Jesuitas en la Amazonía: experiencias de Brasil e Quito. In: HERNÁNDEZ PALOMO, José J. \& MORENO JERIA, Rodrigo (Coord.) La misión y los jesuítas en la América Española, 1566-1767. Cambios y permanencias. Sevilha: Consejo Superior de Investigaciones Científicas, Escuela de Estudios Hispano-Amerincanoss, 2005, p. 151-186.

FAUSTO, Carlos. Os índios antes do Brasil. Rio de Janeiro: Jorge Zahar Ed., 2000. 
FRITZ, Samuel. Diário del Padre Fritz. Edición de Hernán Rodriguez Castelo, Quito, 1997.

HOLANDA, Sérgio Buarque de. História Geral da Civilização Brasileira. A Época Colonial. São Paulo: DIFEL, 1981.

MATOS, Maria Izilda S. Navegando pelo Rio das Amazonas. Imagens de Gênero nas crônicas de viagem. Ensaios. Disponível em <http://www.klickescritores.com.br/ pag_materias/riodasamazonas.pdf>. Acessado em 05 de março de 2006.

MIGÑOLO, Walter D. Cartas, crónicas y relaciones del descubrimiento y de la conquista. In: MADRIGAL, Iñigo (ed). Historia de la literatura hispanoamericana (Época colonial). Madrid: Cátedra, 1982, pp. 57-116.

MONTOYA, Antonio Ruiz de. Conquista Espiritual. Hecha por los Religiosos de la Compañía de Jesus en las províncias de Paraguay, Parana, Uruguay y Tape. (1639) Estudio preliminar y notas Dr. Ernesto J. A. Maeder. Rosario: Equipo Difusor de Estudios de Historia Iberoamericana, 1989.

PASTOR, Beatriz. Discursos narrativos de la conquista: mitificación y emergencia. Hanover: Ediciones del Norte, 1988.

PEDRO, Juliana de Castro. Embates pela memória: narrativas de descoberta nos escritos coloniais da Amazônia Ibérica. Dissertação (Mestrado em História) Pontifícia Universidade Católica de São Paulo, 2006. Disponível em: <http:/ /www.dominiopublico.gov.br/download/texto/cp008079.pdf>. Acessado em 05 de dezembro de 2006.

PORRO, Antonio. As Crônicas do rio Amazonas. Notas Etno-Históricas sobre as antigas populações indígenas da Amazônia. Petrópolis: Vozes, 1993. "História indígena do alto e médio Amazonas: séculos XVI a XVIII." In: CUNHA, Manuela Carneiro da (org.). História dos índios do Brasil. São Paulo: Cia das Letras, Secretaria Municipal de Cultura: FAPESP, 1992, p. 175-196.

PRATT, Mary Louise. Os olhos do império: relatos de viagem e transculturação. Bauru: Edusc, 1999.

ROJAS, Alonso de. Relación del Descubrimiento del Rio de las Amazonas y sus dilatadas Províncias y Relación del Descubrimiento del río de las Amazonas, hoy San Francisco de Quito, y declaración del mapa onde está pintado ... (1640). In: CARVAJAL, ALMESTO \& ROJAS, A de. La aventura del Amazonas. Ed. de Rafael Díaz. Madrid: História 16, 1986 (Crônicas de América 19). 
SCHWARTZ, Stuart B. e LOCKART, James. A América Latina na época colonial. Rio de Janeiro: Civilização Brasileira, 2002.

TAYLOR, Anne Christine. História pós-colombina da alta Amazônia. In: CUNHA, Manuela Carneiro da (org.). História dos índios do Brasil. São Paulo: Cia das Letras, Secretaria Municipal de Cultura: FAPESP, 1992, p. 213-238.

TUPIASSU, Amarílis. Amazônia, das travessias lusitanas à literatura de até agora. Estudos Avançados, São Paulo, v. 19, n. 53, 2005. Disponível em: <http://www.scielo.br/ scielo.php?script=sci_arttext\&pid=S0103-40142005000100019\&lng=pt\&nrm=iso $>$. Acessado em 08 de abril de 2007.

UGARTE, Auxiliomar Silva. Margens Míticas: a Amazônia no imaginário europeu do século XVI. In: DEL PRIORE, Mary e GOMES, Flávio (org.). Os Senhores dos Rios. Amazônia, Margens e Histórias. Rio de Janeiro: Elsevier, 2003, p. 03-31. 